\title{
HPV-negative tumors of the uterine cervix
}

\author{
Inmaculada Nicolás $\mathbb{1}^{1,2} \cdot$ Lorena Marimon ${ }^{2,3} \cdot$ Esther Barnadas $^{2,3} \cdot$ Adela Saco $^{3} \cdot$ Leonardo Rodríguez-Carunchio ${ }^{3}$. \\ Pere Fusté $^{1} \cdot$ Cristina Martí $^{1} \cdot$ Adriano Rodriguez-Trujillo $^{1} \cdot$ Aureli Torne $^{1} \cdot$ Marta del Pino $^{1} \cdot$ Jaume Ordi $^{2,3}$
}

Received: 19 September 2018 / Revised: 21 December 2018 / Accepted: 22 December 2018 / Published online: 25 March 2019

(c) United States \& Canadian Academy of Pathology 2019

\begin{abstract}
Human papillomaviruses (HPV) are the causative agents of virtually all cervical carcinomas. Nevertheless, a small proportion of cervical cancer are negative for HPV, although the significance of this finding remains unclear. We aimed to provide insight into the differential clinico-pathological characteristics of this unusual subset of HPV-negative cervical cancer. We performed HPV-DNA detection using a highly sensitive PCR test (SPF10) and p16 immunostaining in 214 cervical carcinomas specimens from women treated at the Gynecological Oncology Unit of the Hospital Clinic (Barcelona, Spain) from 2012 to 2015. The clinical and pathological characteristics, including disease-free survival and overall survival, of HPV-negative and -positive cervical carcinomas were compared. Twenty-one out of 214 tumors (10\%) were negative for HPV DNA. HPV-negative tumors were more frequently of the non-squamous type $(9 / 21,43 \%$ vs. $37 / 193,19 \% ; p<0.01)$ and showed negative p16 staining $(9 / 21 ; 43 \%$ vs. $7 / 193 ; 4 \% ; p<0.01)$. HPV-negative tumors were more frequently diagnosed at advanced FIGO stage $(19 / 21,91 \%$ vs. $110 / 193,57 \% ; p<0.01)$ and more frequently had lymph node metastases $(14 / 21,67 \%$ vs. $69 / 193,36 \% ; p<0.01)$. Patients with HPV-negative cervical cancer had a significantly worse disease-free survival (59.8 months, $95 \%$ confidence interval $32.0-87.6$ vs. 132.2 months, $95 \%$ confidence interval $118.6-145.8 ; p<0.01$ ) and overall survival (77.0 months, $95 \%$ confidence interval $47.2-106.8$ vs. 153.8 months, $95 \%$ confidence interval 142.0 165.6; $p=0.01$ ) than women with HPV-positive tumors. However, only advanced FIGO stage and lymph node metastases remained associated with a poor disease-free survival and overall survival on multivariate analysis. In conclusion, our results suggest that a low percentage of cervical cancer arise via an HPV-independent pathway. These HPV-negative tumors are diagnosed at advanced stages, show higher prevalence of lymph nodes metastases and have an impaired prognosis.
\end{abstract}

\section{Introduction}

Cervical cancer is the fourth most common cancer in women worldwide and is one of the leading causes of morbidity and mortality [1]. Human papillomaviruses

These authors contributed equally: Marta del Pino, Jaume Ordi

Senior authorship: Marta del Pino, Jaume Ordi.

Jaume Ordi

jordi@clinic.cat

1 Institute Clinic of Gynecology, Obstetrics, and Neonatology, Hospital Clínic - Institut d'Investigacions Biomèdiques August Pi i Sunyer (IDIBAPS), University of Barcelona, Barcelona, Spain

2 Institut de Salut Global de Barcelona (ISGlobal), Barcelona, Spain

3 Department of Pathology, Hospital Clínic, University of Barcelona, Barcelona, Spain
(HPV), specifically high-risk genotypes, have been identified as the causative agents for the development of this tumor $[2,3]$. Indeed, HPV is identified in virtually all cervical cancer and premalignant cervical lesions (high grade intraepithelial lesions/cervical intraepithelial neoplasia grade 2-3 [HSIL/CIN2-3] and adenocarcinoma in situ) [2-8]. However, despite the development of highly sensitive tests for molecular detection of HPV in recent years [9-13] and irrespectively of the technique used for HPV detection, a small proportion of cervical cancer are consistently negative for HPV in almost all studies [2, 14-16].

Interestingly, two carcinogenetic pathways have been clearly characterized in other anatomical areas in which HPV is involved in carcinogenesis such as the vagina [17], the vulva [18], and the head and neck region [19, 20]. In all these anatomical regions, a variable proportion of tumors are associated with HPV, whereas the remaining cases arise through mechanisms independent of HPV. Remarkably, in anatomical locations other than the uterine cervix, HPVassociated carcinomas have consistently shown a better 
prognosis than HPV-independent tumors [17-20]. In contrast, it has not been conclusively established whether HPVnegative carcinomas in the uterine cervix are a distinct subset of tumors with different epidemiologic and biologic behavior, as suggested by some reports [15], or whether they merely represent false negative results of HPV detection techniques. Neither is there any clear evidence showing that these tumors have different clinical and prognostic characteristics.

Therefore, it is necessary to provide more insight into the clinical and pathological characteristics of this unusual group of cervical cancers which are negative for HPV. In the present study, we aimed to analyze HPV status in a large series of cervical cancer using a highly sensitive polymerase chain reaction (PCR) technique and p16 immunohistochemical analysis, a surrogate marker of HPV infection [21], to determine the characteristics of HPV-negative cervical cancer tumors.

\section{Materials and methods}

\section{Study design}

The study included all women admitted to the Gynecological Oncology Unit of the Hospital Clinic from Barcelona who fulfilled the following inclusion criteria: (1) histological diagnosis of cervical cancer; (2) a paraffin block from the tumor with available tumor tissue for HPV-DNA testing and p16 immunostaining.

From January 2012 to December 2015, 217 women with a diagnosis of cervical cancer were identified. One case was reclassified as endometrial adenocarcinoma after histological review. Two cases in which no material was available for molecular analysis were excluded. Thus, 214 samples were finally included in the study.

Demographic and clinico-pathological features (age, smoking habit, clinical presentations, histological type, International Federation of Gynecology and Obstetrics [FIGO] stage and nodal status) and follow-up data were recorded. The study was approved by the Ethics Committee of Clinical Research of the Hospital Clinic (registry HCB/ 2015/0517).

\section{Study protocol}

Upon referral, all women underwent a complete clinical evaluation by a gynecological oncologist following the clinical protocols of the Gynecological Oncology Unit of our center. In the first visit, a biopsy of the tumor was performed for histological confirmation, a thorough clinical examination was made to determine the FIGO stage, and a complete blood analysis and pre-treatment imaging evaluation (abdominopelvic magnetic resonance imaging and/or computerized tomography scan) were performed. The imaging evaluation was performed by a radiologist with expertise in gynecological oncology in order to confirm the primary location of the tumor in the uterine cervix.

\section{Clinical management and treatment}

Women with stage IA1 tumors underwent the loop electrosurgical excision procedure or extra-fascial hysterectomy. Patients with stages IA2, IB1, or IIA underwent laparoscopy with an intraoperative sentinel lymph node evaluation. Patients with negative sentinel lymph nodes were treated with either radical vaginal hysterectomy assisted by laparoscopy or radical trachelectomy, while patients with positive sentinel nodes underwent selective pelvic and complete para-aortic lymphadenectomy without hysterectomy, followed by chemo-radiotherapy. Patients with FIGO stage IB2, IIB, or III underwent a complete paraaortic lymphadenectomy with selective pelvic lymphadenectomy removing all suspicious or enlarged lymph nodes, followed by chemo-radiotherapy. A systematic pelvic lymphadenectomy was not part of the routine procedure as pelvic lymph nodes are included within the radiation field in women with locally advanced cervical cancer. However, selective excision of pelvic lymph nodes was performed on identification of enlarged lymph nodes by imaging techniques or during the surgical procedure. Women with disseminated disease (Stage IV) were treated with chemoradiotherapy or palliative treatment.

Chemo-radiotherapy was administered simultaneously with radiation therapy. All patients received brachytherapy and external beam radiation to the pelvic region and to the aortic area if metastasic para-aortic lymph nodes.

\section{Histological evaluation and immunohistochemical detection of p16 and p53}

All the specimens from the cervix and/or the lymph nodes were retrieved for histological evaluation. The samples had been routinely formalin-fixed and paraffin-embedded. A gynecological pathologist evaluated all the cases. The histological diagnosis was based on hematoxylin and eosin (H\&E) morphological criteria, but immunostaining (vimentin estrogen receptors, cytokeratins 7 and 20, carcinoembryonic antigen, etc.) were used when necessary to exclude secondary cervical involvement by other neoplasms. Immunohistochemical analysis was performed with the Autostainer Link 48 (Dako Co., Carpinteria, CA, USA), using the EnVision system (Dako).

All tumors were stained with p16 (CINtec Histology Kit, clone E6H4; Roche-Mtm-Laboratories, Heidelberg, Germany). Only cases with diffuse and strong nuclear and 
cytoplasmic staining in all viable tumor cells were considered positive for $\mathrm{p} 16$, whereas cases with irregular or focal staining were considered negative. Keratotic areas were excluded from the p16 evaluation.

Immunostaining detection of p53 was only performed in tumors with negative HPV-DNA testing (clone DO-7; Dako). p53 staining was scored as normal (p53n), probably representing a "wild-type" protein, when at least a few nuclei of the tumor cells showed weak to moderate staining comparable to the staining pattern observed in the adjacent normal tissue. Two staining patterns were defined as "p53 abnormal" (p53abn) and suggestive of mutated p53: (i) strong overexpression of all tumor cells, and (ii) completely absent staining in the tumor cells, with a positive internal control showing a wild-type pattern [22-24].

\section{Tissue preparation and nucleic-acid isolation}

DNA extraction and HPV genotyping was performed in formalin-fixed and paraffin-embedded tissue of either the pre-treatment biopsy or the surgical specimen. The samples were serially sectioned with a microtome. The first and last sections $(3 \mu \mathrm{m})$ were stained with $\mathrm{H} \& \mathrm{E}$ for histological confirmation of the diagnosis. In between sections were collected in RNAase-free reaction tubes for DNA isolation (sandwich cutting technique). Sectioning and sample preparation were carried out with the highest measures to avoid contamination and cross-contamination. Paraffin blocks lacking tissue were cut in between the patient samples as controls to ensure the lack of contamination.

DNA was extracted by overnight incubation in $20 \mu \mathrm{L}$ of proteinase $\mathrm{K}$ solution $(1 \mathrm{mg} / \mathrm{mL})$ at $56{ }^{\circ} \mathrm{C}$. Subsequently, proteinase $\mathrm{K}$ was heat-inactivated by incubation of the sections at $95^{\circ} \mathrm{C}$ for $10 \mathrm{~min}$, and samples were spun down and cooled down at $-20{ }^{\circ} \mathrm{C}$ for $1-2 \mathrm{~min}$. DNA was isolated using a commercially available kit (QIAamp Tissue Kit; Qiagen, Hilden, Germany), according to the manufacturer's instructions. DNA yields were quantified spectrophotometrically using the NanoDrop ND-1000 (Thermo Scientific NanoDrop, Wilmington, DE, USA).

\section{DNA amplification for HPV detection and genotyping}

To assess the quality of the DNA, $\beta$-globin PCR analysis was performed using the primers BGPCO3 and BGPCO5, as described elsewhere [15]. PCR products were analyzed by electrophoresis on a $1.5 \%$ agarose gel. All samples were $\beta$-globin PCR-positive, indicating adequate DNA quality.

A volume of $10 \mu \mathrm{L}$ of isolated DNA were used for PCR amplification, using the SPF10-LiPA system (Fujirebio, Gent, Belgium) as described previously [25, 26]. HPV typing was performed using the INNO-LiPA HPV
Genotyping Extra II kit (Fujirebio, Ghent, Belgium). This system allows the amplification and typing of high-riskHPV types (16, 18, 31, 33, 35, 39, 45, 51, 52, 56, 58, 59, and 68$)$, probably high-risk-HPV types $(26,53,66,70,73$, and 82$)$ and low-risk-HPV types $(6,11,40,42,43,44,54$, $61,62,67,81,83,89)$. Each run contained negative and positive controls to monitor the efficiency of DNA isolation, PCR amplification, hybridization, and genotyping procedures. None of these negative control samples were positive in the HPV PCR assay, indicating adequate avoidance of contamination.

Finally, a subset of eight HPV-negative tumors were tested for the presence of high-risk-HPV E7 DNA using a sensitive E7 multiplex PCR, enabling the detection of 14 high-risk-HPV types $(16,18,31,33,35,39,45,51,52,56$, $58,59,66,68)[27]$.

\section{Data analysis}

The SPSS 23.0 (SPSS, Chicago, IL, USA) statistical package was used for the statistical analysis. Categorical variables were expressed as absolute numbers and percentages. The chi-square exact test was used to compare qualitative variables. Quantitative variables were expressed as means and standard deviation, and the $T$ test was used for comparisons. For data analysis, FIGO stages IA1 to IB1 were considered as early FIGO staging and FIGO stages IB2 to IV were referred as advanced FIGO staging. Diseasefree survival was defined as the time from diagnosis to the first local recurrence or metastasis. Overall survival was defined as the time from the date of diagnosis to the date of death or to the last date of follow-up. Death without documented progression was censored at the date of death. Survival data were analyzed with the Kaplan-Meier method, and survival curves were compared using the logrank test and the level of significance adopted was 0.05 . Univariate and multivariate Cox models were used to analyze prognostic factors (histology, HPV status, p16 staining, FIGO stage and lymph node status). The hazard ratio with a 95\% confidence interval was calculated for risk estimation. The multivariate Cox model included variables that showed statistical significance in the univariate models.

\section{Results}

Twenty-one out of the 214 tumors (10\%) included were negative for HPV DNA. Table 1 shows the comparison between the clinical and pathological characteristics of the patients with HPV-negative and -positive cervical cancer. Patients with HPV-negative tumors were older and were more frequently diagnosed due to clinical symptoms such as hemorrhage or abdominal pain. HPV-negative tumors were 
Table 1 Clinical and histological characteristics of the patients with HPV-negative and -positive tumors

\begin{tabular}{|c|c|c|c|}
\hline & $\begin{array}{l}\text { HPV-negative } \\
(n=21)\end{array}$ & $\begin{array}{l}\text { HPV-positive } \\
(n=193)\end{array}$ & $p$ \\
\hline $\mathrm{Age}^{\mathrm{a}}$ & $58(16)$ & $51(15)$ & 0.04 \\
\hline Smokers & $6(29)$ & $82(42)$ & 0.22 \\
\hline Clinical presentation & & & $<0.01$ \\
\hline Clinical symptoms & $20(95)$ & $119(62)$ & \\
\hline Abnormal Pap smear & $1(5)$ & $74(38)$ & \\
\hline Histological type & & & $<0.01$ \\
\hline $\begin{array}{l}\text { Squamous cell } \\
\text { carcinoma }\end{array}$ & $12(57)$ & $156(80)$ & \\
\hline Adenocarcinoma & $6(29)$ & $33(17)$ & \\
\hline $\begin{array}{l}\text { Adenosquamous } \\
\text { carcinoma }\end{array}$ & $1(5)$ & $3(2)$ & \\
\hline $\begin{array}{l}\text { Neuroendocrine } \\
\text { carcinoma }\end{array}$ & $2(9)$ & $1(1)$ & \\
\hline p16 & & & $<0.01$ \\
\hline Positive & $12(57)$ & $186(96)$ & \\
\hline Negative & $9(43)$ & 7 (4) & \\
\hline Tumor size $(\mathrm{mm})^{*}$ & $55(22.4)$ & $36.8(21.2)$ & $<0.01$ \\
\hline FIGO stage & & & $<0.01$ \\
\hline Early (IA-IB1) & $2(10)$ & $83(43)$ & \\
\hline Advanced (IB2-IV) & $19(90)$ & $110(57)$ & \\
\hline Relapse & $7(33)$ & $42(22)$ & 0.27 \\
\hline Lymph node metastasis & $14(67)$ & $69(36)$ & $<0.01$ \\
\hline
\end{tabular}

${ }^{a}$ Values are given as absolute numbers and percentages or mean and standard deviation

more frequently of the non-squamous type $(9 / 21,43 \%$ vs.37/193, 19\%; $p<0.01)$ and negative for p16. HPVnegative tumors were more frequently diagnosed at advanced FIGO stage and more frequently had lymph node metastases. No information was available on whether these patients attended, or not, regular cervical cancer screening.

Table 2 shows the age, the histological type, the p16 and p53 immunostaining patterns and the follow-up data of the $21 \mathrm{HPV}$-negative cervical cancer. HPV E7 PCR was performed in eight tumors (6/12 HPV-negative, p16 positive, and 2/9 HPV-negative, p16 positive cases). All samples tested were negative for E7 PCR.

All adenocarcinomas were of the conventional mucinous type and ten out of the $12(83 \%)$ squamous cell carcinomas were non-keratinizing. Out of the 21 tumors, 9 (43\%) showed negative p16 staining and 15/21 (71\%) HPVnegative tumors showed a p53abn immunostaining pattern. No clinical or histological differences were found between HPV-negative/p16 positive tumors vs. p16 negative staining or between a p53nm vs. p53abn immunostaining pattern (data not shown). Nevertheless, patients with HPV-negative/p16 positive tumors more frequently showed a p53abn immunostaining pattern compared with HPV-negative/p16 negative specimens $(10 / 12,83 \%$ vs. $5 / 9,56 \% ; p=0.01)$.

The median follow-up was 61 months $(95 \%$ confidence interval 54.5-67.5 months). Figure 1 shows the disease-free survival (Fig. 1a) and the overall survival (Fig. 1b) of the patients included in the study according to HPV status. Patients with HPV-negative cervical cancer had a significantly worse disease-free survival (59.8 months [95\% confidence interval: $32.0-87.6]$ vs. 132.2 months [95\% confidence interval: $118.6-145.8] ; p<0.01)$ and overall survival (77.0 months [95\% confidence interval 47.2 106.8 ] vs. 153.8 months [95\% confidence interval 142.0 165.6]; $p=0.01$ ) than women with HPV-positive tumors.

The results of the univariate and multivariate analysis for disease-free progression and mortality are shown in Tables 3 and 4, respectively. HPV negativity, p16 immunostaining negative, advanced FIGO stage, and lymph node metastases were associated with a poor disease-free survival and increased tumor-associated mortality in the univariate analysis. However, only the FIGO stage and lymph node metastases remained associated with a poor disease-free survival and overall survival in the multivariate analysis.

On analyzing squamous cell carcinomas separately, patients with HPV-negative tumors $(n=12)$ were more frequently diagnosed due to clinical symptoms than women with HPV-positive $(n=156)$ neoplasms and were more frequently diagnosed at advanced FIGO staging (Table 5). Patients with HPV-negative squamous cell carcinomas had a significantly worse disease-free survival (47.6 months [95\% confidence interval: $10.5-84.7]$ vs. 130.7 months [95\% confidence interval: 115.5-145.9]; $p<0.01$ ) and overall survival $(70.0$ months $[95 \%$ confidence interval 27.3-112.7] vs. 150.0 months [95\% confidence interval 136.6-163.5]; $p=0.04$ ) compared to women with HPVpositive tumors. Although HPV was associated with relapse and mortality risk (Hazard Ratio: 2.9, 95\% confidence interval 1.3-6.5, $p<0.01$; and Hazard Ratio: 2.5, 95\% confidence interval 1.0-6.4, $p=0.05$, respectively) on univariate analysis, only lymph node metastases and advanced FIGO staging remained associated with a worse prognosis on multivariate analysis (data not shown).

\section{Discussion}

The most relevant finding of our study is that women with HPV-negative tumors were more frequently diagnosed at advanced stages, had a higher rate of lymph node metastasis and an impaired disease-free survival and overall survival. In this study, HPV-negative tumors represented a small percentage of cervical cancer (10\%). These results are in keeping with previous reports, including a previous study 
Table 2 Molecular, histological, and clinical characteristics of the patients with HPV-negative tumors in the genotyping analysis

\begin{tabular}{|c|c|c|c|c|c|c|c|c|c|c|c|}
\hline Case & Age & Histological type & p16 & p53 & E7 PCR & FIGO & LN metastases & Relapse & Months & Status & Follow-up \\
\hline 1 & 64 & SCC, non-keratinizing & - & $\mathrm{nm}$ & $\mathrm{np}$ & IIIB & Yes & No & - & ANED & 140.0 \\
\hline 2 & 57 & SCC, sarcomatoid & - & $\mathrm{nm}$ & $\mathrm{np}$ & IVA & Yes & No & - & DOD & 7.3 \\
\hline 3 & 83 & SCC, non-keratinizing & - & abn & $\mathrm{np}$ & IIIB & Yes & No & - & AWD & 4.2 \\
\hline 4 & 69 & Neuroendocrine carcinoma & - & abn & $\mathrm{np}$ & IVB & Yes & No & - & DOD & 0.5 \\
\hline 5 & 85 & SCC, non-keratinizing & - & $\mathrm{nm}$ & $\mathrm{np}$ & IIIA & Yes & Yes & 34.5 & AWD & 40.9 \\
\hline 6 & 51 & Neuroendocrine carcinoma & - & $\mathrm{nm}$ & np & IIIB & Yes & No & - & DOD & 2.2 \\
\hline 7 & 49 & ADC, mucinous & - & abn & Negative & IIIB & Yes & Yes & 22.8 & AWD & 39.9 \\
\hline 8 & 41 & ADC, mucinous & - & abn & $\mathrm{np}$ & IIB & No & No & - & ANED & 70.5 \\
\hline 9 & 61 & SCC, keratinizing & - & abn & Negative & IIB & Yes & Yes & 19.3 & DOD & 48.1 \\
\hline 10 & 53 & SCC, non-keratinizing & + & abn & $\mathrm{np}$ & IIIB & No & No & - & AWD & 31.6 \\
\hline 11 & 54 & ADC, mucinous & + & abn & $\mathrm{np}$ & IIIB & Yes & No & - & DOD & 33.3 \\
\hline 12 & 36 & Adenosquamous carcinoma & + & $\mathrm{nm}$ & Negative & IIB & No & No & - & ANED & 116.2 \\
\hline 13 & 82 & ADC, mucinous & + & abn & np & IIIB & Yes & No & - & ANED & 40.3 \\
\hline 14 & 38 & SCC, non-keratinizing & + & $a b n$ & np & IB1 & No & No & - & ANED & 72.5 \\
\hline 15 & 53 & SCC, non-keratinizing & + & $a b n$ & $\mathrm{np}$ & IIIB & Yes & No & - & AWD & 2.0 \\
\hline 16 & 32 & ADC, mucinous & + & $a b n$ & Negative & IB1 & No & No & - & ANED & 63.0 \\
\hline 17 & 64 & SCC, non-keratinizing & + & abn & Negative & IIB & Yes & Yes & 7.5 & DOD & 16.9 \\
\hline 18 & 40 & SCC, non-keratinizing & + & abn & Negative & IIIB & No & Yes & 6.7 & DOD & 6.7 \\
\hline 19 & 66 & ADC, mucinous & + & $\mathrm{nm}$ & Negative & IVB & Yes & Yes & 26.7 & DOD & 36.4 \\
\hline 20 & 54 & SCC, non-keratinizing & + & abn & $\mathrm{np}$ & IIB & No & Yes & 11.4 & AWD & 24.5 \\
\hline 21 & 80 & SCC, non-keratinizing & + & abn & Negative & IVA & Yes & No & - & DOD & 0.1 \\
\hline
\end{tabular}

$L N$ lymph node, $S C C$ squamous cell carcinoma, $A D C$ adenocarcinoma, $A N E D$ alive with no evidence of disease, $A W D$ alive with disease, $D O D$ died of disease, $n m$ p53 normal, $a b n$ p53 abnormal, $n p$ not performed

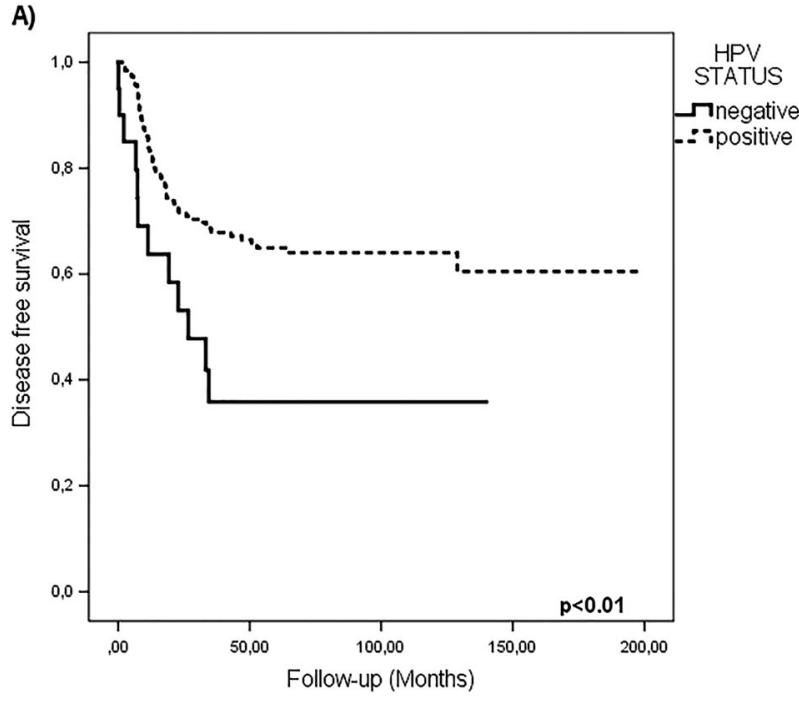

Fig. 1 Kaplan-Meier analysis of human papillomavirus (HPV) status in all the cases included in the study. HPV-negative cases include 21 patients and HPV-positive cases include 193 patients. a Disease-free survival (time from diagnosis to the first local recurrence or

conducted by our group with a smaller series of cervical cancer [15, 28-30].

Although it is generally accepted that HPV is a necessary cause of cervical cancer, almost all studies consistently

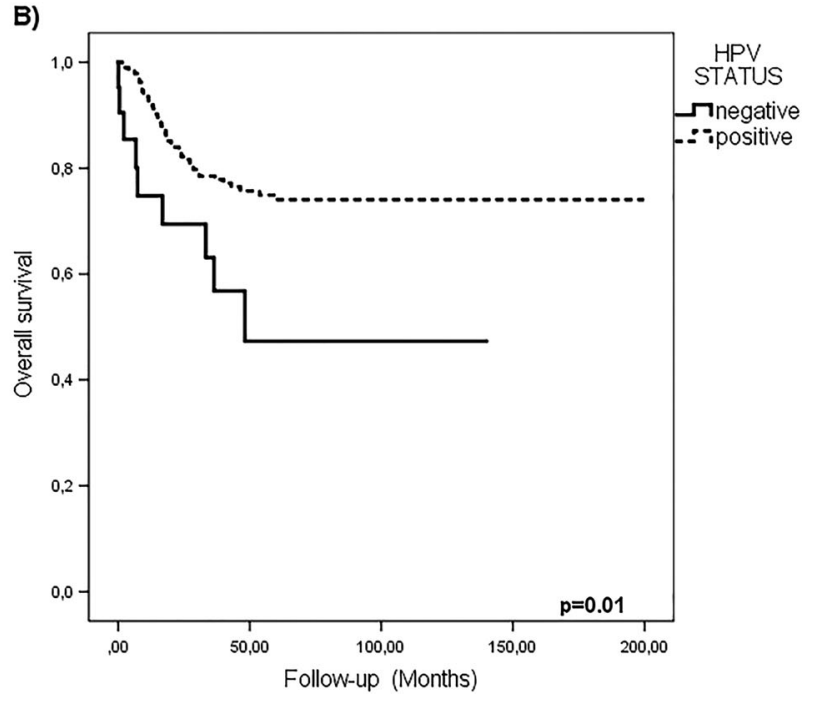

metastasis); b Overall survival (time from the date of diagnosis to the date of death or to the last date of follow-up). Deaths without documented progression were censored at the date of death. Survival curves were compared using the log-rank test

show a proportion of tumors, ranging from 4 to $52 \%$, that are negative for HPV detection [2, 29, 31-34]. The low sensitivity of some HPV-testing methods when applied to formalin-fixed and paraffin-embedded tissues is likely to be 
Table 3 Univariate and multivariate Cox models for relapse

\begin{tabular}{|c|c|c|c|c|c|c|}
\hline & \multicolumn{3}{|c|}{ Univariate Cox model } & \multicolumn{3}{|c|}{$\begin{array}{l}\text { Multivariate Cox } \\
\text { model }\end{array}$} \\
\hline & HR & $95 \% \mathrm{CI}$ & $p$ & HR & CI $95 \%$ & $p$ \\
\hline Non SCC histology & 0.9 & $0.5-1.6$ & 0.85 & - & - & - \\
\hline Negative HPV status & 2.4 & $1.3-4.4$ & $<0.01$ & 1.1 & $0.5-2.5$ & 0.81 \\
\hline p16 negativity & 2.9 & $1.5-5.8$ & $<0.01$ & 1.7 & $0.8-3.9$ & 0.18 \\
\hline Advanced FIGO stage & 5.8 & $3.0-11.3$ & $<0.01$ & 3.6 & $1.7-7.5$ & $<0.01$ \\
\hline $\begin{array}{l}\text { Lymph node } \\
\text { metastasis }\end{array}$ & 4.1 & $2.5-6.6$ & $<0.01$ & 2.4 & $1.4-4.0$ & $<0.01$ \\
\hline
\end{tabular}

$H R$ hazard ratio, $C I$ confidence interval

Table 4 Univariate and multivariate Cox models for mortality

\begin{tabular}{|c|c|c|c|c|c|c|}
\hline & \multicolumn{3}{|c|}{ Univariate Cox model } & \multicolumn{3}{|c|}{$\begin{array}{l}\text { Multivariate Cox } \\
\text { model }\end{array}$} \\
\hline & HR & $95 \% \mathrm{CI}$ & $p$ & HR & CI $95 \%$ & $p$ \\
\hline Non SCC histology & 0.7 & $0.3-1.5$ & 0.35 & - & - & - \\
\hline $\begin{array}{l}\text { Negative HPV } \\
\text { status }\end{array}$ & 2.5 & $1.2-5.1$ & 0.01 & 0.9 & $0.4-2.3$ & 0.44 \\
\hline p16 negative & 3.5 & $1.6-7.4$ & $<0.01$ & 1.9 & $0.8-5.1$ & 0.14 \\
\hline $\begin{array}{l}\text { Advanced FIGO } \\
\text { stage }\end{array}$ & 43.7 & $\begin{array}{l}6.0- \\
316.5\end{array}$ & $<0.01$ & 23.8 & $\begin{array}{l}3.1- \\
177.6\end{array}$ & $<0.01$ \\
\hline $\begin{array}{l}\text { Lymph node } \\
\text { metastasis }\end{array}$ & 7.1 & $3.7-13.7$ & $<0.01$ & 3.2 & $1.7-6.0$ & $<0.01$ \\
\hline
\end{tabular}

$H R$ hazard ratio, $C I$ confidence interval

Table 5 Clinical and histological characteristics of the patients with squamous cell carcinoma according to HPV status

\begin{tabular}{|c|c|c|c|}
\hline & $\begin{array}{l}\text { HPV-negative } \\
(n=12)\end{array}$ & $\begin{array}{l}\text { HPV-positive } \\
(n=156)\end{array}$ & $p$ \\
\hline $\operatorname{Age}^{a}$ & $61(15)$ & $52(15)$ & 0.65 \\
\hline Smokers & $4(33)$ & $70(45)$ & 0.49 \\
\hline Clinical presentation & & & $<0.01$ \\
\hline Clinical symptoms & $12(100)$ & $98(63)$ & \\
\hline $\begin{array}{l}\text { Abnormal Pap } \\
\text { smear }\end{array}$ & $0(0)$ & $58(37)$ & \\
\hline p16 & & & $<0.01$ \\
\hline Positive & $7(58)$ & $151(97)$ & \\
\hline Negative & $5(42)$ & $5(3)$ & \\
\hline Tumor size $(\mathrm{mm})^{*}$ & $54.8(25.3)$ & $38.2(21.1)$ & 0.01 \\
\hline FIGO stage & & & 0.04 \\
\hline Early (IA-IB1) & $1(8)$ & $59(38)$ & \\
\hline $\begin{array}{l}\text { Advanced (IB2- } \\
\text { IV) }\end{array}$ & $11(92)$ & $97(62)$ & \\
\hline Relapse & $5(42)$ & $32(21)$ & 0.08 \\
\hline $\begin{array}{l}\text { Lymph node } \\
\text { metastasis }\end{array}$ & $8(67)$ & $62(40)$ & 0.06 \\
\hline
\end{tabular}

${ }^{a}$ Figures are absolute numbers and percentages or means and standard deviation the cause of the high prevalence of HPV-negative tumors observed in some studies [29]. Poor-quality DNA of the tumor specimens and histological misclassification by inclusion of endometrial neoplasms as cervical adenocarcinomas have also been proposed as possible causes of false HPV-negative results in cervical cancer [6]. In our study, the quality of the DNA was assessed by evaluating $\beta$ globin in all of the samples, and all were found to be adequate. In addition, a gynecological pathologist confirmed all the histological diagnoses after careful review, which included imaging data and immunostaining to exclude tumors of non-cervical origin when required. In this study, in order to exclude the possibility of false HPV negativity due to a viral integration, we have also analyzed in a subset of samples, the presence of HPV E7 DNA by PCR targeting E7, in addition to the detection of the DNA of the HPV. All cases were negative for E7 DNA, confirming that they were truly HPV negative. However, the design of our study does not allow to conclude whether the HPV-negative cervical cancers represented the clearance of the HPV in tumors initially HPV-associated [6] or whether they were truly HPV-independent tumors. In any case, if HPV negativity is related to an impaired prognosis, it should be considered for the clinical management of these patients.

Several studies have shown that HPV-negative cervical cancers are mostly adenocarcinomas, and that some specific subtypes such as clear cell, mesonephric, or gastric-type adenocarcinomas account for most of the HPV-negative cervical cancers [2, 16, 20, 31, 35-37]. In our study, adenocarcinomas were indeed more frequently HPV-negative than squamous cell carcinomas, but in contrast with previously published series [16], most were of the conventional mucinous type. Interestingly, in our study a significant proportion of HPV-negative cervical cancers were histologically squamous cell carcinomas. Moreover, although HPV-negative squamous cell carcinomas are usually considered to be very well differentiated $[17,18]$, most of the tumors in our series were of the conventional non-keratinizing subtype.

As shown in other studies, most HPV-positive tumors showed a strong and diffuse overexpression of p16 [15, 17 20]. However, a significant proportion (57\%) of HPVnegative tumors were positive for p16. The absence of the HPV E7 DNA in this subset of tumors is an additional evidence that confirms the absence of association with HPV. Interestingly, the HPV-negative cervical cancer with p16 overexpression showed a high rate of the p53abn immunostaining pattern suggestive of mutation (83\%), supporting the hypothesis that, $\mathrm{p} 16$ overexpression in some of these cervical cancers might be induced independently of HPV, and this could represent a higher mutation capacity of the tumor. Previous studies have shown a relation between the mutational status of p53 and poor prognosis [22, 38, 39]. In our series, 15/21 (71\%) patients with an HPV-negative status presented 
p53abn. This mutational phenotype of the HPV-negative cervical cancers, could explain a higher capacity of tumor deregulation, with increased growth potential and metastasis, and a worse prognosis. These results are in keeping with previous reports in other anatomical areas [17-21].

In our study, HPV-negative tumors were diagnosed at more advanced FIGO stages and showed a higher rate of lymph node metastasis. FIGO stage and lymph node status are considered the most important prognostic parameters for cervical cancer [40]. In fact, it is of note that in the present series almost all the HPV-negative tumors (19/21: 91\%) were diagnosed at advanced stages, which could justify their impaired prognosis. These data also agree with previous studies showing that HPV-negative tumors frequently show factors of poor prognosis [38, 41, 42] and suggest that HPV-negative tumors might be a more aggressive subtype of cervical cancer. In this regard, a recent meta-analysis including data from 2838 patients with cervical cancer reported in 17 different studies concluded that HPV-positive cervical cancers have a better prognosis [43]. The poor prognosis of HPV-negative carcinomas compared with HPV-positive tumors has also been observed in other locations in which HPV-associated and HPV-independent carcinomas have been described. Indeed, in the head and neck and the vaginal region, HPV-positive tumors have consistently shown a better prognosis than HPV-negative neoplasms [17-19]. Remarkably, in the present series, the HPV-negative squamous cell carcinomas showed the same clinical and prognostic differences when compared with the HPV-positive squamous cell carcinomas, that is, they were more commonly diagnosed at an advanced stage, had a higher rate of lymph node metastasis and an impaired disease-free survival and overall survival.

The main strength of our study is that it includes a large number of cases with cervical cancer, and that the HPV status was evaluated using highly sensitive PCR and immunohistochemistry techniques. The main limitation of our study is the small number of HPV-negative cervical cancers. However, given the low frequency of these tumors, even large referral centers are only able to retrieve a very small number of women with these neoplasms. Thus, large multi-center studies are warranted to confirm the impaired prognosis of this subset of cervical cancers. Another possible limitation might be the use of formalin-fixed and paraffin-embedded samples, which could have had an impact on the quality of DNA, and subsequently, the results of HPV-DNA testing [15, 29, 43]. However, the quantity of DNA was quantified spectrophotometrically, and the quality of the DNA was confirmed by $\beta$-globin PCR in all of the samples.

In conclusion, although further studies are required to confirm these data, our results suggest that a low percentage of cervical cancer arise via an HPV-independent pathway and have an impaired prognosis similar to counterparts in other anatomical sites with both HPV-associated and independent tumors.

Acknowledgements We thank Donna Pringle for the English revision of the article.

Funding This research was funded in part by Instituto de Salud Carlos III (ICSIII)-Fondo de Investigación Sanitaria, and ERDF “One Way to Europe" (PI17/00772).

\section{Compliance with ethical standards}

Conflict of interest The authors declare no conflict of interest.

Publisher's note: Springer Nature remains neutral with regard to jurisdictional claims in published maps and institutional affiliations.

\section{References}

1. Ferlay J, Soerjomataram I, Ervik M, Dikshit R, Eser S, Mathers C, et al. GLOBOCAN 2012 v1.0, Cancer Incidence and Mortality Worldwide: IARC CancerBase No. 11. Lyon, France: International Agency for Research on Cancer; 2013.

2. de Sanjose S, Quint WG, Alemany L, Geraets DT, Klaustermeier JE, Lloveras B, et al. Human papilomavirus genotype attribution in invasive cervical cancer: a retrospective cross-sectional worldwide study. Lancet Oncol. 2010;11:1048-56.

3. Bosch FX, Burchell AN, Schiffman M, Giuliano AR, de Sanjose $\mathrm{S}$, Bruni L, et al. Epidemiology and natural history of human papilomavirus infections and type-specific implications in cervical neoplasia. Vaccine. 2008;26:1-16.

4. El-Mofty SK, Lu DW. Prevalence of high-risk human papillomavirus DNA in nonkeratinizing (cylindrical cell) carcinoma of the sinonasal tract: a distinct clinicophatololic and molecular disease entity. Am J Surg Pathol. 2005;29:1367-72.

5. Bishop JA, Guo TW, Smith DF, Wang H, Ogawa T, Pai SI, et al. Human Papillomavirus-related carcinomas of the sinonasal tract. Am J SurgPathol. 2013;37:185-92.

6. Alemany L, Pérez C, Tous S, Llombart-Bosch A, Lloveras B, Lerma E, et al. Human papillomavirus genotype distribution in cervical cancer cases in Spain. Implication for prevention. GynecolOncol. 2012;124:512-7.

7. Clifford GM, Smith JS, Plummer M, Muñoz N, Franceschi S. Human papillomavirus types in invasive cervical cancer worldwide: a meta-analysis. Br J Cancer. 2003;88:63-73.

8. Walboomers JM, Jacobs MV, Manos MM, Bosch FX, Kummer JA, Shah KV, et al. Human papillomavirus is a necessary cause of invasive cervical cancer worldwide. J Pathol. 1999; 189:12-9.

9. Arbyn M, Haelens A, Desomer A, Verdoodt F, Thiry N, Francart $\mathrm{J}$, et al. Cervical cancer screening program and Human Papillomavirus (HPV) testing, part II: Update on HPV primary screening. KCE Reports 238. Health Technology Assessment (HTA). Brussels: Belgian Health Care Knowledge Centre (KCE); 2015.

10. Heideman DAM, Hesselink AT, Berkhof J, van Kemenade F, Melchers WJ, Daalmeijer NF, et al. Clinical validation of the cobas $4800 \mathrm{HPV}$ test for cervical screening purposes. J ClinMicrobiol. 2011;49:3983-5.

11. Torné A, Del Pino M, Cuisidó M, Alameda F, Andia D, Castellsagué $\mathrm{X}$, et al. Guía de cribado del cáncer de cuello de útero en España, 2014. RevEsp Patol. 2014;47:1-43. 
12. Massad LS, Einstein MH, Huh WK, Katki HA, Kinney WK, Schiffman M, et al. 2012 updated consensus guidelines for the management of abnormal cervical cancer screening tests and cancer precursors. J Low Genit Tract Dis. 2013;17:1-27.

13. Khan MJ, Castle PE, Lorincz AT, Wacholder S, Sherman M, Scott DR, et al. The elevated 10-year risk of cervical precancer and cancer in women with human papillomavirus (HPV) type 16 or 18 and the possible utility of type-specific HPV testing in clinical practice. J Natl Cancer Inst. 2005;97:1072-9.

14. Chong GO, Lee YH, Han HS, Lee HJ, Park JY, Hong DG, et al. Prognostic value of pre-treatment human papilloma virus DNA status in cervical cáncer. GynecolOncol. 2018;148:97-102.

15. Rodriguez-Carunchio L, Soveral I, Steenbergen RDM, Torné A, Martinez S, Fusté P, et al. HPV-negative carcinoma of the uterine cervix: a distinct type of cervical cancer with poor prognosis. BJOG. 2015;122:119-27.

16. Park KJ, Kiyokawa T, Soslow RA, Lamb CA, Oliva E, Zivanovic $\mathrm{O}$, et al. Unusual endocervical adenocarcinomas: an immunohistochemical analysis with molecular detection of human papillomavirus. Am J SurgPathol. 2011;35:633-46.

17. Alonso I, Felix A, Torne A, Fusté V, del Pino M, Castillo P, et al. Human papillomavirus as a favorable prognostic biomarker in squamous cell carcinomas of the vagina. GynecolOncol. 2012;125:194-9.

18. Nooij LS, Ter-Haar NT, Ruano D, Rakislova N, van Wezel T, Smit VTHBM, et al. Genomic characterization of vulvar (pre) cancers identifies distinct molecular subtypes with prognostic significance. Clin Cancer Res. 2017;23:6781-9.

19. Alos L, Moyano S, Nadal A, Alobid I, Blanch JL, Ayala E, et al. Human papillomaviruses are identified in a subgroup of sinonasal squamous cell carcinomas with favorable outcome. Cancer. 2009;115:2701-9.

20. Larque AB, Hakim S, Ordi J, Nadal A, Diaz A, del Pino M, et al. High-risk human papillomavirus is transcriptionally active in a subset of sinonasal squamous cell carcinomas. Mod Pathol. 2014;27:343-51.

21. Rakislova N, Clavero O, Alemany L,Saco A, Quirós B, Lloveras $\mathrm{B}$, et al. Histological characteristics of HPV-associated and -independent squamous cell carcinomas of the vulva: a study of 1.594 cases. Int J Cancer. 2017;141:2517-27.

22. Silva DC, Gonçalves AK, Cobucci RN, Mendonça RC, Lima $\mathrm{PH}$, Cavalcanti G. Immunohistochemical expression of p16, Ki-67 and p53 in cervical lesions-a systematic review. Pathol Res Pract. 2017;213:723-29.

23. Zhou R, Wei C, Liu J, Luo Y, Tang W. The prognostic value of p53 expression for patients with cervical cancer: a meta analysis. Eur J Obstet Gynecol Reprod Biol. 2015;195:210-13.

24. McCluggage WG, Soslow RA, Gilks CB. Patterns of p53 immunoreactivity in endometrial carcinomas: 'all or nothing' staining is of importance. Histopathology. 2011;59:786-88.

25. Kleter B, van Doorn LJ. Novel short-fragment PCR assay for highly sensitive broad-spectrum detection of anogenital human papillomaviruses. Am J Pathol. 1998;153:1731-39.

26. Kleter B, van Doorn LJ, Schrauwen L, Molijn A, Sastrowijoto $\mathrm{S}$, ter Schegget J, et al. Development and clinical evaluation of a highly sensitive PCR-reverse hybridization line probe assay for detection and identification of anogenital human papillomavirus. $\mathbf{J}$ Clin Microbiol. 1999;37:2508-17.

27. Hesselink A, Berkhof J, van der Salm ML, van Splunter AP, Geelen TH, van Kemenade FJ, et al. Clinical validation of the HPV-Risk assay: a novel, real-time PCR assay for the detection of high-risk human papillomavirus DNA by targeting the E7 region. J Clin Microbiol. 2014;52:890-6.
28. del Pino M, Rodríguez-Carunchio L, Alonso I, Torné A, Rodriguez A, Fusté P, et al. Clinical, colposcopic and pathological characteristics of cervical and vaginal high-grade lesions negative for HPV by Hybrid Capture 2. Gynecol Oncol. 2011;122:515-20.

29. Barreto CL, Martins DB, De Lima Filho JL, Magalhães V. Detection of Human Papillomavirus in biopsies of patients with cervical cancer, and its association with prognosis. Arch GynecolObstet. 2013;288:643-8.

30. Tao X, Zheng B, Yin F, Zeng Z, Li Z, Griffith CC, et al. Polymerase chain reaction Human Papillomavirus (HPV) -detection and HPV genotyping in invasive cervical cancers with prior negative HC2 test results. Am J ClinPathol. 2017;147:477-83.

31. Li N, Franceschi S, Howell-Jones R, Snijders PJ, Clifford GM. Human papillomavirus type distribution in 30,848 invasive cervical cancers worldwide: variation by geographical region, histological type and year of publication. Int $\mathrm{J}$ Cancer. 2011;128:927-35.

32. Guan P, Howell-Jones R, Li N, Bruni L, de Sanjosé S, Franceschi $\mathrm{S}$, et al. Human papillomavirus types in $115,789 \mathrm{HPV}$-positive women: a meta-analysis from cervical infection to cancer. Int $\mathrm{J}$ Cancer. 2012;131:2349-59.

33. Igidbashian S, Schettino MT, Boveri S, Barberis M, Sandri MT, Carinelli S, et al. Tissue genotyping of 37 in situ and invasive cervical cancer with a concomitant negative HC2 HPV DNA test. J Low Genit Tract Dis. 2014;18:87-91.

34. Lai CH, Huang HJ, Hsueh S, Chao A, Lin CT, Huang SL, et al. Human papillomavirus genotype in cervical cancer: a populationbased study. Int J Cancer. 2007;120:1999-2006.

35. Andersson S, Larson B, Hjerpe A, Silfverswärd C, Sällström $\mathrm{J}$, Wilander E, et al. Adenocarcinoma of the uterine cervix: the presence of human papillomavirus and the method of detection. Acta Obstet Gynecol Scand. 2003;82:960-5.

36. Clifford G, Franceschi S. Members of the human papillomavirus type 18 family (alpha-7 species) share a common association with adenocarcinoma of the cervix. Int J Cancer. 2008;122:1684-5.

37. Tornesello ML, Losito S, Benincasa G, Fulciniti F, Botti G, Greggi S, et al. Human papillomavirus (HPV) genotypes and HPV16 variants and risk of adenocarcinoma and squamous cell carcinoma of the cervix. GynecolOncol. 2011;121:32-42.

38. Riou G, Favre M, Jeannel D, Bourhis J, Le Doussal V, Orth G. Association between poor prognosis in early-stage invasive cervical carcinomas and non-detection of HPV DNA. Lancet. 1990;335:1171-74.

39. Crook T, Vousden KH. Properties of p53 mutations detected in primary and secondary cervical cancers suggest mechanusms of metastasis and involvement of environmental carcinogens. EMBO J. 1992;11:3935-40.

40. Zampronha R, de A, Freitas-Junior R, Murta EF, Michelin MA, Barbaresco AA, Adad SJ, et al. Human papillomavirus types 16 and 18 and the prognosis of patients with stage I cervical cancer. Clinics (Sao Paulo). 2013;68:809-14.

41. Pilch H, Gunzel S, Schaffer U, Tanner B, Brockerhoff P, Maeurer $\mathrm{M}$, et al. The presence of HPV DNA in cervical cancer: correlation with clinic-pathologic parameters and prognostic significance: 10 years experience at the Department of Obstetrics and Gynecology of the Mainz University. J Gynecol Cancer. 2001;11:39-48.

42. Feng $\mathrm{D}, \mathrm{Xu} \mathrm{H}, \mathrm{Li} \mathrm{X}$, Wei $\mathrm{Y}$, Jiang $\mathrm{H}, \mathrm{Xu} \mathrm{H}$, et al. An association analysis between mitocondrial DNA content, G10398A polymorphism, HPV infection, and the prognosis of cervical cáncer in the Chinese Han population. Tumour Biol. 2016;37:5599-607.

43. Li P, Tan Y, Zhu LX, Zhou LN, Zeng P, Liu Q, et al. Prognostic value of HPV DNA status in cervical cancer before treatment: a systematic review and meta-analysis. Oncotarget. 2017;8:66352-9. 